\title{
A Relationship Analysis between Green Supply Chain Management and its Performance: A Path Analytic Model
}

\author{
Seigo Matsuno*, Shin-ya Tagawa, Yasuo Uchida \\ Dept. of Business Administration, Ube National College of Technology, Ube, Yamaguchi 755-8555, Japan \\ Takao Ito \\ Graduate School of Engineering, Hiroshima University, Higashi-Hiroshima, Hiroshima 739-8527, Japan
}

*Corresponding author, E-mail: matsuno@ube-k.ac.jp

Tel: +81-836-35-4016, Fax: +81-836-35-4016

\begin{abstract}
This paper proposes and empirically tests a model of the relationship between green supply chain management (GSCM) practices and corporate performance. Based on a literature review, we identified five determinants, namely, environmental commitment, supplier collaboration, supplier assessment, information sharing among suppliers, and business process improvement that are used as determinants in a structural model which influence environmental and economic performance. The model was analyzed using the data from a survey of sample of Japanese manufacturing firms. The results suggest that the degree of supplier collaboration has an influence on the environmental performance directly. Meanwhile, the impact of supplier assessment on the environmental performance is mediated by the information sharing and/or business process improvement. Furthermore, we find positive relationship between environmental performance and economic performance.
\end{abstract}

Keywords: Green supply chain management, Corporate performance, Empirical study, Path modeling

\section{Introduction}

Green supply chain management (GSCM) is an interfirm collaborative initiative concerning environmental load reduction and environmental preservation throughout the entire life cycle of a product. Against a backdrop of an international trend of tightening regulations on specific chemical substances, as typified by the Restriction of Hazardous Substances (RoHS) Directive and/or Registration, Evaluation, Authorization and Restriction of Chemicals (REACH), as well as social demands for environmental load reduction and preservation, a heightening of environmental awareness among consumers, and other factors, many firms have engaged in GSCM activities in recent years [1]-[8].

However, along with the pursuit of economic efficiency throughout the entire supply chain, which is the main focus of conventional supply chain management, GSCM also seeks to achieve environmental load reduction, and many issues related to GSCM require investigation, for example, 
examination of cost effectiveness. In addition, the development of inter-firm information systems and information transfer format standardization are urgently required; REACH in Europe, for instance, requires the communication and sharing of chemical substances information between agents/partners in supply chains.

This paper is organized as follows. In Section 2, we briefly review some relevant researches about the effectiveness of GSCM implementation. We analyze the status of GSCM implementation at firms in Japan on the basis of our original questionnaire survey and also consider the relationship between GSCM practices and performance, focusing on the role of inter-firm information sharing in Section 3. Section 4 presents a structural equation model concerning factors that affect GSCM performance and use path analysis to test the validity of the model. Finally in Section 5 we provide the conclusion of this investigation.

\section{Literature review}

A previous research concerning effects obtained from the implementation of GSCM is the empirical study that Zhu and Sarkis (2004) conducted on 281 manufacturing firms in China [7]. They used statistical analysis methods to test effects that GSCM has on environmental and economic performance and whether quality control and JIT activities have a moderator effect on performance. Although the findings showed that GSCM implementation has a positive effect on a firm's environmental performance, they did not provide sufficient conclusion to measure whether the effect on economic performance is positive or negative.

Large and Thomsen (2011) tested the effect that GSCM has on environmental and purchasing performance [2]. After identifying factors that affect GSCM performance on the basis of literature review, they used survey data on purchasing firms in Germany to perform structural equation modeling and tested the validity of their model. Their findings showed that green supplier assessment and active collaboration have a positive effect on environmental performance, and that they are promoted according to the strength of the purchasing department's strategic role and commitment to environmental management. The findings also indicated that improvement in environmental performance has a positive effect on purchasing performance.
In light of the abovementioned previous research, we engage in further explorative discussion concerning GSCM practices and performance at firms in Japan, focusing on the role that inter-firm information sharing plays in GSCM implementation.

\section{Data and analysis}

\subsection{Outline of the survey}

We conducted a mail questionnaire survey from November 2010 to February 2011 with the research objective of investigating "the current state and issues in supply chain greening and inter-firm collaboration”. Since ordinarily the introduction and implementation of GSCM is likely to be affected by firm size, we studied Japanese manufacturers with 500 or more employees in this survey. The number of valid responses obtained from randomly sampled firms was 126, yielding a response rate of $25.2 \%$ (detailed results are omitted here) [9][10].

\subsection{GSCM implementation and internal management}

First, we confirmed the status of implementation of concrete inter-firm cooperation activities in GSCM. We were able to ascertain that many firms provide information and exchange opinions concerning environmental regulations and cooperate concerning the prohibition or reduction of use of regulated chemicals contained in raw materials and components. In addition, we found that some progressive firms implemented the detailed GSCM activities cooperate concerning ecodesign and engage in joint research or joint development of eco-friendly products or materials with business partners under inter-firm cooperation and collaboration.

Then, we confirmed the state of development of internal management systems for overall environmental management. On the whole, high scores were obtained for all questions (based on a 6-point scale), and it was found that the introduction of EMS and development of organizations in charge of environmental management are particularly advanced. It is likely that this state of internal management systems development shows the strength of overall commitment to environmental management, including the implementation of GSCM. 


\subsection{Supplier assessment}

We analyzed what sort of requirements manufacturing firms have for suppliers concerning implementation of GSCM and, on the other hand, what sort of assistance they provide.

We confirmed that many firms have a variety of requests for suppliers. For example, request that suppliers understand each firm's environmental philosophy and requiring them to observe a code of conduct or guidelines. Also, although the scores are comparatively low, there are firms that conduct on-site environmental inspections of suppliers and engage in continuous auditing and monitoring, and support the development of suppliers' EMS.

\subsection{GSCM implementation and information sharing among firms}

We examined the status of information communication/exchange activities through information networks among firms.

Information communication/exchange between firms via information networks occurs mainly with respect to information about purchase order placement/receipt or suppliers/customers, and information about billing, payment, and settlement. At the same time, we found that detailed communication/exchange between firms also occurs with respect to information about components and measured values of regulated chemicals.

The background to this is likely progress in preparations for and compliance with REACH, which went into effect in June 2007 in Europe. REACH requires communication and sharing of chemical substances information between agents in supply chains. Confirmation for matters such as the presence or absence and the content of chemical substances subject to regulation in molded articles is required, as is such information from manufacturers as applications and amount used by application for each chemical substance.

\subsection{GSCM implementation and performance}

We confirmed awareness among firms of the status of matters such as business process improvement accompanying GSCM implementation. And we confirmed awareness among firms of improvements in environmental and economic performance resulting from GSCM implementation.

Here, we consider quantitative reduction of various types of waste, regulated chemicals, and the like to be environmental performance, and reduction of various costs, such as purchasing and distribution costs, to be economic performance. Although it is necessary to also examine improvement in economic performance on the basis of financial indicators such as sales and profit margins, it is generally difficult to eliminate from these financial indicators the impact of factors other than GSCM implementation. Accordingly, in this paper we perform analysis in which the concept of economic performance is limited to the abovementioned cost reductions.

On the whole, above-average scores are given for both environmental and economic performance improvement. However, firms do not enjoy the reduction in purchasing and distribution costs.

\section{Path analysis concerning GSCM practices and performance}

In light of the above analysis, we present a structural equation model concerning factors that affect GSCM performance [11]. The hypothetical path model is shown in Fig. 1.

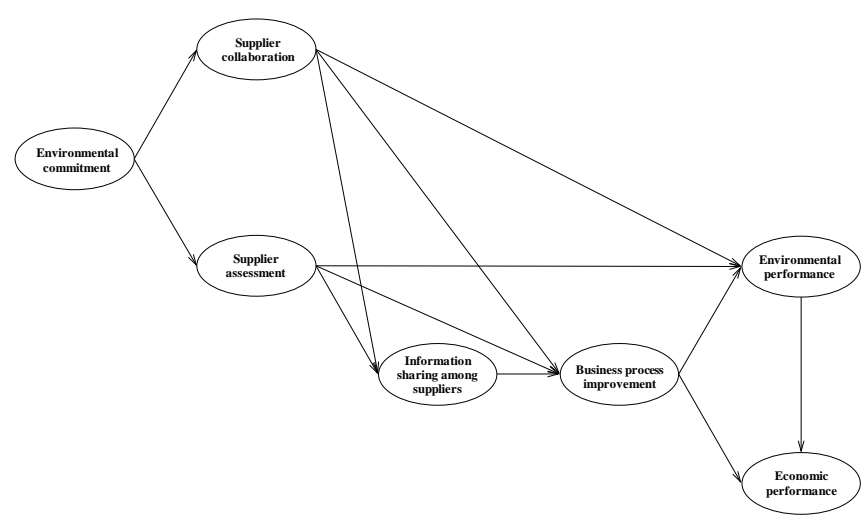

Fig. 1. Hypothetical path model

The model uses the seven composite variables that is to say, Environmental commitment (5 items), Supplier collaboration (7 items), Supplier assessment (6 items), Information sharing among suppliers (3 items), Business process improvement (3 items), and Environmental performance (5 items) as explanatory variables and Economic performance (4 items) as the 
dependent variable, and assumes a causal chain at multiple stages. We assume a positive path in all relationships between the factors.

Next, we provide an overview of the path analysis. Here, we omit the factor analysis process for examining the validity of the assumed latent variables and use the value obtained by dividing the total of the values of the items pertaining to each latent variable by the number of items. In other words, we use composite scales to represent the latent variables. Table 1 shows the descriptive statistics of each variable. For each scale, Cronbach's $\alpha$ is greater than 0.8 , and reliability (internal consistency) is high.

Table 1. Descriptive statistics of variables (composite scales)

\begin{tabular}{lcccc}
\hline & $\begin{array}{c}\text { \# of } \\
\text { items }\end{array}$ & $\alpha$ & Mean & S.D. \\
\hline Environmental commitment & 5 & 0.93 & 4.75 & 0.99 \\
Supplier collaboration & 7 & 0.89 & 3.77 & 1.03 \\
Supplier assessment & 6 & 0.88 & 3.64 & 1.19 \\
Information sharing among suppliers & 3 & 0.81 & 2.70 & 1.31 \\
Business process improvement & 3 & 0.87 & 3.34 & 1.05 \\
Environmental performance & 5 & 0.89 & 3.48 & 1.16 \\
Economic performance & 4 & 0.86 & 3.07 & 1.13 \\
\hline
\end{tabular}

Note: each score on a 6-point scale

We empirically test the path model using these variables, performing sequential multiple linear regression analysis using the standard partial regression coefficient as the path coefficient.

When we took Environmental commitment, Supplier collaboration, and Supplier assessment as explanatory variables and Information sharing among suppliers as the explained variable, no significant positive path from Supplier collaboration was found. That is to say, some non-significant paths were found in the causal chain between factors that affect GSCM performance. However, all other paths were significant at the $1 \%$ or $5 \%$ level. Also, all coefficients of determination were significant, and the relationships between factors assumed in this paper were almost supported (Fig. 2).

\section{Conclusion}

This paper proposes and empirically tests a model of the relationship between GSCM practices and corporate performance. We identified five constructs, namely, environmental commitment, supplier collaboration, supplier assessment, information sharing among suppliers, and business process improvement.

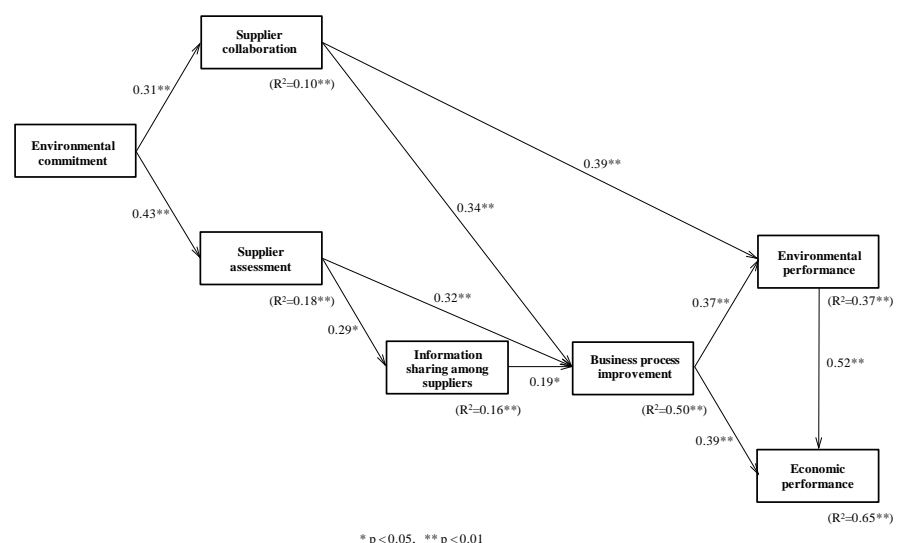

Fig. 2. Approved path model

The results suggest that the degree of supplier collaboration has an influence on the environmental performance directly. While, the impact of supplier assessment on the environmental performance is mediated by the information sharing and/or business process improvement. And, environmental performance has a positive impact on economic performance.

\section{Acknowledgments}

This research was partly supported by the Japan Society for the Promotion of Science, Grant-in-Aid for Scientific Research (C) 24530445 and authors would like to thank the organization.

\section{References}

1. S. Hoejmose, S. Brammer and A. Millington, Green supply chain management: The role of trust and top management in B2B and B2C markets, Industrial Marketing Management 41(4) (2012) 609-620.

2. R. Large and C. Thomsen, Drivers of green supply management performance: Evidence from Germany, Journal of Purchasing and Supply Management 17(3) (2011) 176-184.

3. M. Lopez-Gamero, J. Molina-Azorin and E. ClaverCortes, The whole relationship between environmental variables and firm performance: Competitive advantage and firm resources as mediator variables, Journal of Environmental Management 90(10) (2009) 3110-3121

4. S. Matsuno, M. Hasama and T. Ito, Greening of the supply chain and its impact on information sharing among firms based on the transaction cost economics (in 
Japanese), Transactions of the Japan Society for Production Management 17(3) (2011) 11-16

5. F. Testa and F. Iraldo, Shadows and lights of GSCM: determinants and effects of these practices based on a multi-national study, Journal of Cleaner Production 18(10-11) (2010) 953-962.

6. S. Yang, C. Lu, J. Haider and P. Marlow, The effect of green supply chain management on green performance and firm competitiveness in the context of container shipping in Taiwan, Transportation Research Part E: Logistics and Transportation Review 55 (2013) 55-73.

7. Q. Zhu and J. Sarkis, Relationships between operational practices and performance among early adopters of green supply chain management practices in Chinese manufacturing enterprises, Journal of Operations Management 22(3) (2004) 265-289.

8. Q. Zhu, J. Sarkis and K. Lai, Green supply chain management innovation diffusion and its relationship to organizational improvement: An ecological modernization perspective, Journal of Engineering and Technology Management 29(1) (2012) 168-185.

9. S. Matsuno, Y. Mikami and T. Ito, An analysis of green supply chain management practices and its performance focused on the role of information sharing among firms (in Japanese), Transactions of the Japan Society for Production Management 18(2) (2012) 11-16.

10. S. Matsuno and S. Tokinaga, Greening of the supply chain and its impact on corporate networks: Analysis based upon a questionnaire survey (in Japanese), Journal of Information and Management 32(4) (2012) 23-30.

11. S. Matsuno, M. Hasama, Y. Uchida and T. Ito, Green supply chain management activities and corporate performance: Evidence from Japan, in Proc. of the 1st Int. Conf. of Production Management (Ho Chi Minh, Vietnam, 2013), Ref. \#053, CD-ROM. 